\title{
SPECIAL DOCUMENT 10 YEARS PAHO BIOETHICS UNIT (1994-2004)
}

$\mathrm{O}$ n January $13^{\text {th }}$, 1994, an agreement was signed between the Director of the Pan American Health Organization (PAHO), the Rector of the University of Chile, the Chilean Minister of Health and the Chilean Minister of Foreign Affairs, acting as privileged witness the Chilean President of the Republic. The agreement created the Regional Program on Bioethics and established it in Santiago de Chile as part of the Division of Health and Human Development.

On January $14^{\text {th }}$ and $15^{\text {th }}, 2004$, the tenth anniversary of the Program was celebrated with a special session held at the same place where the original agreement was signed. It coincided with the Fourth Meeting of the International Advisory Board on Bioethics, composed by experts from different backgrounds who provide advice for the activities of the Regional Program, now called Bioethics Unit, and for a part of the Area of Information and Knowledge Management (IKM) at $\mathrm{PAHO}^{1}$.

The brief description that follows is part of the material describing current activities of the Bioethics Unit, a joint venture between PAHO, the University of Chile, and the Chilean Government. The information should be complemented with what is published at the website http://www.bioetica.ops-oms.org and http://www.uchile.cl/bioetica

\section{The Bioethical Perspective}

It has become widely accepted that health is not only a problem for health professionals but a problem for society at large, in whose resolution people from all sectors should participate. The bioethical discourse attempts to generate strategies and to articulate social concerns in the pursuit of general well

The members of this Committee designated for the period 2003-2004 are: Dr. Derrick E. Aarons, Physician, Bioethicist; Dr. Daniel Callahan, Director of International Programs, The Hastings Center; Alexander Capron, Director Ethics and Health Program (DGO/ETH), World and Health Organization; Norman Daniels, Ph.D., Professor of Ethics and Population Health, Department of Population and International Health, Harvard School of Public Health; Dr. Diego Gracia Guillén, Departamento de Salud Pública e Historia de la Ciencia, Universidad Complutense de Madrid; Dr. Pedro Federico Hooft Lauterslager, Profesor Titular Universidad Nacional de Mar del Plata; Dr. Bernardo Klisksberg, General Coordinator Office of the Inter-American Initiative on Social Capital, Ethic and Development; Sana Loue, J.D., Ph.D., M.P.H., Associate Professor of Bioethics, Associate Professor of Epidemiology and Biostatistics, Assistant Professor of International Health Center for Biomedical Ethics, Case Western Reserve University; Alfonso Llano Escobar S.J., Director, Instituto de Bioética - CENALBE, Pontificia Universidad Javeriana; Dr. Ruth Macklin, Department of Epidemiology and Social Medicine, Albert Einstein College of Medicine; Dr. Victor B. Penchaszadeh, Professor of Pediatrics, Chief Division of Medical Genetics, Beth Israel Medical Center; Dr. Leocir Pessini, Vicerector Centro Universitario São Camilo; Dr. Peter A. Singer, Sun Life Financial Chair in Bioethics and Director University of Toronto Join Centre for Bioethics. 
- being. As social institutions, ethics committees and other forms of bioethical praxis allow the joint consideration of technical, scientific, and valoric aspects of interventions on the healthcare system.

The integration of bioethical decision-making processes to the technical aspects of health promotion and protection emphasizes the fact that all interventions can be viewed from the perspective of professionals and users and might serve as a paradigmatic approach to other projects in the health field. As a major immediate impact, it should demonstrate that valoric considerations permeate all aspects of the healthcare enterprise and should be taken into account at the inception of any project or program.

As in the 1999 document, the notions of proactive, rather than reactive, ethical reflection and the "ethical sustainability" of projects, reforms, or interventions continue to inspire the work of the Bioethics Unit at PAHO. Of special concern now and then is the "moral vulnerability" in which the populations of our countries live, subject to political and economic decisions in which they not always take part.

\section{Human resources}

Emphasis has been placed on the training of adequate numbers of professionals conversant with bioethics principles and methods, so that they can participate in the administration of healthcare resources and contribute to the dialog between different stakeholders. Throughout the 10-year period between 1994 and 2004, courses at masters' level have been taught at different universities in the Latin American and Caribbean (LAC) region, and some of the former students are now acting in their countries in positions relevant to both health care and health research.

In association with the University of Chile, the Complutense University of Madrid, and a consortium of several institutions (Universidad Nacional Mayor de San Marcos, Lima; Instituto Tecnológico de Santo Domingo, Dominican Republic; Universidad Nacional de Cuyo, Mendoza, Argentina; Universidad Nacional de Córdoba, Argentina, among others) several masters' programs have been developed and implemented in the region, along with monographic courses and contribution to programs of other academic institutions.

A Fogarty International Center (NIH, USA) grant to the University of Chile has permitted the development of a training program in research ethics under the model of a career award administered jointly by the Interdisciplinary Center for Bioethical Studies at the University of Chile and the PAHO Bioethics Unit (details at the website http://www.uchile.cl/bioetica).

The Perú-US Forum for Research Ethics, a joint undertaking of the main Peruvian 
universities and the Uniformed Services University for the Health Sciences, USA, has also received technical advice and contribution from the Bioethics Unit.

In addition, the introduction of bioethics to medical school curricula, the discussion of the particular didactics relevant to bioethics training and teaching, and the elaboration of databases listing the teaching and training programs in the countries of the Latin American and Caribbean Region have also become part of the routine work of the Bioethics Unit.

\section{Surveys and studies}

As part of the work of the Bioethics Unit, several surveys and studies are regularly conducted.

Relevant among them are analyses of the situation of ethical oversight in the research funding agencies in the Latin American and Caribbean Region, studies of the biomedical publications, information about legislation with bioethical impact in the countries of the LAC Region, and several projects in association with the Center at the University of Chile (Social representation of genomics, ethical review committees and their functioning, among others). The Unit is open to suggestions about other information which could be collected and disseminated.

\section{Information and publications}

The Bioethics Unit has maintained publication of the scholarly journal "Acta Bioethica" (ISSN 0717-5906) published twice a year in monographic format with invited contributions and peer-reviewed articles. The journal is available in electronic PDF format free to download and is sent to all PAHO Representations, universities, and libraries.

It also publishes the quarterly newsletter "Bioética Informa" aimed at informing about events and developments in the Region (also available in electronic format).

Additionally, several books and monographs have been published. It is usual for the International Advisory Board's meetings to include an academic section and its members are invited to contribute with papers which are published afterwards in book form. A complete list of those publications, including fulltext versions, is available at the website of the Bioethics Unit.

Databases used by the Bioethics Unit include RedBIO, a complete listing of persons and institutions, as well as training programs and academic facilities.

The Virtual Library on Bioethics, available since several months, was presented in January 2004 for general access and represents one project in conjunction with BIREME. Other joint undertakings include the edition of a se- 
ries of interviews and conferences published as DVD ("Diálogos en Bioética" in English and Spanish, including interviews with prominent bioethicists such as Diego Gracia, Daniel Callahan, James Drane, Alfonso Llano, Jan Broekman, among others).

Two series of "comics" or illustrated stories dealing with selected topics of the history of science and reproductive medicine have been produced in association with the University of Chile ("Viajeros Virtuales" and "Entretecho"), funded by the Chilean Commission for Science and Technology and the Ford Foundation, among other sources of support. A third series of stories, dealing with the history of medicine, is in preparation (the first episode, the history of diabetes and insulin discovery, is already available).

The documentation center at the Bioethics Unit provides service to all interested in bioethical matters, honoring requests for information from PWRs, universities, and individuals in general.

\section{Support to PAHO Representations and Ministries of Health}

The Bioethics Unit receives many requests for information and support from PWRs and government officials and honors them without delay. Some of them involve provision of information resources, speakers for conferences, clarification of issues regarding legislation, research issues, etc.

\section{Emerging issues}

Bioethics is involved in many different areas, so that the contacts and networks which can be activated by the Bioethics Unit are always prepared to respond to emergent challenges.

\section{An agenda for the future}

Members of the International Advisory Board provide advice on issues such as better use of resources, sources of funding and critical areas of development. Irrespective of the contribution of all scholars and academics in the Latin American and Caribbean Region, the Bioethics Unit welcomes suggestions and additions to its current activities, as well as submissions of manuscripts for Acta Bioethica and news items for the newsletter "Bioética Informa".

All materials and correspondence should be addressed to

Unidad de Bioética OPS-OMS

Providencia 1017 - Piso 7

Santiago de Chile

Tel. 56-2-236 0330 Fax 56-2-346 7219

e-mail: bioetica@chi.ops-oms.org

Website: http://www.bioetica.ops-oms.org 